\title{
Barriers Affecting the Utilization of Dental Health Services among Community Dwelling Older Adults
}

\author{
Nadia Mohamed Hassan Saleh, Lecturer \\ Gerontological Nursing, Faculty of Nursing, Mansoura University \\ Neamit Ibrahim Elemam Ahmed Elashri, Lecturer \\ Gerontological Nursing, Faculty of Nursing, Mansoura University \\ Heba Noshy Abd El-Aziz Mohamed, Lecturer \\ Gerontological Nursing, Faculty of Nursing, Mansoura University
}

\author{
Abdel-Hady El-Gilany, Professor \\ Public Health, Faculty of Medicine, Mansoura University
}

\begin{abstract}
Adequate access to oral health care services becomes essential, as it provides opportunities for health promotion, disease prevention, early diagnosis, and treatment of oral diseases. Objective: Assess the barriers affecting the utilization of dental health services among community dwelling older adults. Setting: The geriatric outpatient clinics of specialized medical hospital, Mansoura University and general hospital, Ministry of Health. Subjects: 612 elderly persons aged 60 years and above. Tools: Older Adults' Socio-demgraphic and Clinical Data Structured Interview Schedule, Older Adults' Barriers to dental care utilization Structured Interview Schedule, Katz and Akpom Scale and Oral Health Assessment Tool (OHAT). Results: The most frequent barriers reported by the elders are high cost of dental services, lack of awareness about the importance of dental checkup, fear of dental procedure, difficult transportation and long distance, and bad past experience. Conclusion: Predictors of dental health visits among elderly were basic and secondary education, enough income, elderly suffering from hypertension, elderly free from liver diseases and elderly with healthy oral status. Recommendations: Design oral health educational program for community dwelling older adults about the importance of oral health routine checkup and the available community dental health services.
\end{abstract}

Keywords: Dental; Health Services Utilization; Elderly; Barriers.

\section{Introduction}

Increasing aging puts many elders at higher risk of dental problems such as tooth loss, dental caries and periodontal disease. In spite of that elderly people have the lowest utilization rate of dental care services among all age group ${ }^{(1)}$. Access to dental care is important to improve and maintain good oral health ${ }^{(2)}$. Poor access to dental care leads to poor oral health and may have devastating effects on overall health such as ulcers and malnutrition ${ }^{(3)}$.

Dental attendance among older people is strongly associated with having some natural teeth, higher social class, and inversely associated with fear ${ }^{(4)}$. London
National Health Service [NHS] data March 2006 showed that the uptake of dental care is highest amongst middle-aged adults and declines with increasing age, with estimated registration rates falling from $56 \%$ in the age group 45-54 year down to $29 \%$ among older adults 75 years and over ${ }^{(5)}$.

Despite the need of older adults for dental care, yet the utilization of dental health services is uncommon. Barriers associated with the utilization of dental health services include cost of services, difficulties obtaining dental appointments, fear of dentists, availability of oral health care services, and access to oral health services $^{(6)}$. In Saudi Arabia the most commonly cited barrier is the cost of dental care, as $62.1 \%$ of older adults stopped their 
dental treatment due to $\operatorname{costs}^{(7)}$. In Damanhour city, Egypt, a study done by El-Lassy, 2014 revealed that barriers to dental clinic visits among elderly living in residential homes was $46.7 \%$, and the majority of them $(88.6 \%)$ reported financial problem as the main barrier ${ }^{(8)}$.

Additional barriers affect the use of dental health services among older adults are shortage of professionals, lack of awareness about the services provided, mental, physical, medication related conditions which may make oral care extremely challenging. Poor health and multiple chronic diseases can prevent elders from obtaining needed dental care. Also, availability of dental services, fear, low income, the distance a person had to travel to get care are other factors ${ }^{(9)}$. Dental barriers are generally not self limiting. If untreated, dental conditions may affect the person's well being and overall quality of life. So that, exploring these barriers together produces more useful and integrated information on need, demand, and oral health outcomes ${ }^{(10)}$.

Achieving and keeping good oral health among the elderly is an important challenge to health care providers. A better understanding of barriers related to use of dental health services by older adults will need to be met and minimizing with different health care strategies including three levels of action to be taken; individual actions such as persistence in finding available care following identification of need. System changes including reducing costs, improving information, ensuring appropriate timing, location of care and good patient management. Societal issues such as reducing isolation and loneliness. Education attainment, finances and social support have also been showed to have an important influence on dental health services utilization $^{(11,12)}$.

\section{Aim of the Study}

The study aims to assess the barriers affecting the utilization of dental health services among community dwelling older adults.

\section{Research Question:}

What are the barriers affecting the utilization of dental health services among community dwelling older adults?

\section{Materials and Method}

\section{Materials}

Design: A descriptive design was used in this study.

Setting: The study was carried out in the geriatric outpatient clinics, namely Diabetes mellitus clinic, Cardiovascular diseases clinic, Endocrinology clinic and gastrointestinal and hepatology clinic at the specialized medical hospital affiliated to Mansoura University and general Mansoura hospital affiliated to Ministry of health.

Subjects: Sample size was calculated online using DSS research.com (http://www.dssresearch.com/knowledgecen ter/toolkitcalculators/samplesizecalculators. aspx). A pervious study conducted in Andhra Pradesh, India revealed that $36 \%$ of elderly visited dentist in the past year Nagarjuna et al. (2016) ${ }^{(13)}$ with alpha error $=5 \%$, study power $=80$ and precision of $5 \%$, then the study sample should be 556 . Ten percent was added to compensate for non-responses thus the final sample size is 612 elderly person.

\section{Inclusion criteria:}

- Aged 60 years and above.

- Willing to participate in the study.

- Able to comprehend and communicate.

Tools: Four tools were used for data collection:

Tool I: Older Adults' Socio-demographic Characteristics and Clinical Data Structured Interview Schedule

This tool was developed by the researchers based on review of related literatures and include two parts: 
Part one: Includes socio-demgraphic data such as age, sex, educational level, occupation before retirement and income.

Part two: Medical health history of the study subjects and history regarding previous visit to dentist, and cause of the last visit.

Tool II: Older Adults' Barriers to Dental Care Utilization Structured Interview Schedule

This tool was developed by the researchers after review of related literatures; it includes questions related to barriers to dental care utilization among elderly such as lack of awareness about the importance of dental checkup, difficult transportation and long distance to the services, fear of dental procedure, high cost of dental ser-vices, bad past experience and infection.

\section{Tool III: Katz and Akpom Scale (1976)}

This scale was developed by Katz and Akpom (1976) $)^{(14)}$, it is originally designed to assess the degree of dependency in performing activities of daily living (ADL). It was translated into Arabic language and validated by Melis and El Shazly (1999) ${ }^{(15)}$. The scale includes six activities of daily living namely, grooming, toileting, eating, dressing, bathing and mobility. The activities of daily living are measured and scored according to the individual's actual performance. A score of 6 means independent; a score from 7 to 12 is partially dependent, while a score from 13 to 18 is dependent.

\section{Tool IV: The Oral Health Assessment Tool (OHAT) for Non-Dental Professionals (2005)}

This tool was developed by Chalmers et al. $(2005)^{(16)}$, it is originally designed to assess the oral health status of older adults. It is a modified version of the Kayser-Jones Brief Oral Health Status Examination Kayser-Jones et al. (1996) ${ }^{(17)}$. This tool consists of eight (8) categories namely lips, tongue, gums and tissues, saliva, natural teeth, dentures, oral cleanliness and dental pain. The response to each category was scored zero (healthy oral cavity), one (oral cavity changes) and two (unhealthy oral cavity). Total scores range from 0 to 16 . A score from 0-3 for those have healthy oral status, a score from 4 to 8 changes in oral health and a score from 9 and more for those who have unhealthy oral status.

\section{Method}

- An official letter was issued from the Faculty of Nursing, Mansoura University and forwarded to the director of geriatric outpatient clinic of specialized medical hospital and general hospital in order to obtain their approval to carry out the study.

- Tool I (Older Adults' Sociodemographic Characteristics and Clinical Data Structured Interview Schedule) and Tool II (Older Adults' Barriers to Dental Care Utilization) were developed by the researchers based on review of related literature.

- Tool IV (Oral Health Assessment Tool for Non-Dental Professionals (2005) was used in the English form by the researchers.

- Study tools were reviewed by seven experts in the field of gerontological nursing and oral health from the faculty of dentistry, as a jury to test its content validity and feasibility and necessary modifications were done.

- A pilot study was carried out on $10 \%$ (62) of the study sample to test and ascertain clarity and feasibility of the study tools and the necessary modifications were done. These were excluded from the study sample.

- Each study subject was interviewed individually by the researcher in the waiting room of the outpatient clinic starting from 9 am to $2 \mathrm{pm}$, every Sunday and Wednesday in the geriatric outpatient clinic of the specialized medical hospital and every Monday and Thursday in outpatient clinic of 
Mansoura general hospital to collect the necessary data.

- The data was collected over a period of six months started from first of December 2017 to the last of May 2018.

\section{Ethical considerations:}

Approval from Faculty of Nursing research ethic committee was obtained. Verbal consent from elderly persons after explanation of the study purpose was obtained. Privacy, confidentiality and anonymity were maintained.

\section{Statistical Analysis}

After data collection, they were coded, to be suitable for computer feeding. The Statistical Package for Social Sciences "SPSS" software version 20.0 was utilized for data analysis and tabulation. The 0.05 level was used as the cut off value for statistical significance. Variables were presented as number and per cent. Chisquared test and crude odds ratio (COR) were used for comparison between groups. Significant predictors of dental health services utilization in bivariate analysis were entered into a logistic regression using the forwards Wald methods and adjusted OR were calculated.

\section{Results}

Table (1) shows the distribution of the study subjects according to their sociodemographic characteristics. The table shows that, the age of the study subjects ranged from 60 to 89 years with a mean of $67.91_{ \pm} 6.56$ years. $81.7 \%$ of the study subjects are aged from 60 years to less than 75 years and $13.7 \%$ aged from 75 years to less than 85 years. Male constituted $54.1 \%$ of the study subjects. $66.8 \%$ are married and the rest were either widow, single or divorced. As for the educational level, 46.3 $\%$ of the study subjects are illiterate, $24.6 \%$ with basic education, $13.4 \%$ secondary education and $6.6 \%$ have university education. Concerning occupation before retirement, $35.6 \%$ of the study subjects are housewives, and $18.4 \%$ employees. While,
$17.4 \%$ were farmers, $13.6 \%$ of them were skilled workers and $3.6 \%$ unskilled workers. As for the monthly income $28.9 \%$ reported it to be enough and save and $71.1 \%$ not enough.

Table (2) shows the distribution of the study subjects according to their medical diagnosis and reasons of visit to dental clinic during the last year. It is observed from the table that, diabetes mellitus was reported by $49.5 \%$ of the study subjects. Hypertension in $35.9 \%$ of them. While musculoskeletal, cardiovascular disorders were reported by the same percent. Hepatic and urological disorders by $16.3 \%$ and $16.0 \%$. The rest $3.9 \%$ of the study subjects reported Cancer. Regarding visit of the study subjects to dental clinic $44.1 \%$ of them visit dental clinic and 55.9\% don't visit dental clinic, the majority $70.4 \%$ reported irregular visit to dental clinic, while $29.6 \%$ reported regular visit to dental clinic. The most common reason reported for dental clinic visit was for extractions $37.1 \%$. While, the least common reasons reported were for inflammation and abscess treatment (1.8\% and $0.8 \%$; respectively).

Table (3) shows the barriers of dental health services utilization of the study subjects during the last year. The table shows that the most frequent barriers reported by the study subjects were high cost of dental services $80.0 \%$, followed by their lack of awareness about the importance of dental checkup $74.2 \%$, fear of dental procedure $63.1 \%$, difficult transportation and long distance $60.0 \%$, bad past experience $47.2 \%$ and infection $20.4 \%$.

Table (4): shows the relation between socio-demographics characteristics of the study subjects and dental health visits during the last year. It is observed from the table that $44.1 \%$ of the study subjects visited dentist in the last year. The probability of visiting dentists in the last year is significantly higher among young elderly $\left(\mathrm{COR}_{=} 2.4\right)$, while no statistical significant difference was observed between male and female regarding visits to dentist in last year. Dental health visits is 
significantly higher among elderly with secondary and University education (COR were 11.4 and 4.1; respectively). Also elderly who were employee before retirement $\left(\mathrm{COR}_{=} 7.9\right)$ and elderly with enough income $(C O R=2.2)$ reported higher dental health visits.

Table (5) shows the relation between medical diagnosis and dental health visits of the study subjects during the last year. It is observed from the table that dental health visits in the last year is significantly higher among elderly who have diabetes mellitus and hypertension (COR were 1.9 and 1.8; respectively) and those free from liver diseases $\left(\mathrm{COR}_{=} 2.7\right)$.

Table (6) reveals the relation between oral health status and ability of the study subject to perform ADL and dental health visits during the last year. The table reveals that dental health visits in the last year is significantly higher among elderly with healthy oral status compared to those with changes and unhealthy oral status $\left(\mathrm{COR}_{=}\right.$ 6.7). Also, dental health visits in the last year is significantly higher among independent elderly compared to those partially dependent and dependent in performing activities of daily living $\left(\mathrm{COR}_{=}\right.$ 3.1).

Table (7) shows the regression analysis of dental health visits in last year and its associated independent factors. It is shown that the independent predictors of dental health visits were basic and secondary education $\left(\mathrm{AOR} \_0.6\right.$ and 3.8 respectively), enough income $\left(\mathrm{AOR}_{=} 1.8\right)$, elderly suffering from hypertension and those free from hepatic disorders $\left(\mathrm{AOR}_{=} 2.2\right.$ and 2.2 respectively). Also, elderly who have healthy oral status with a score of (0-3) $\left(\mathrm{AOR}_{=} 2.9\right)$.

\section{Discussion}

Although oral health is crucial to the well-being and overall health of older adults yet they are infrequent users of dental services ${ }^{(18)}$. This highlights the need to improve access to oral health care services as a high priority in the promotion of good oral health in older adults ${ }^{(13)}$. Oral health of older adults is a basic need that is increasingly neglected with age ${ }^{(19)}$. Therefore; this study was conducted in order to determine the barriers affecting the utilization of dental health services among community dwelling older adults.

Visiting the dentist regularly can help to prevent oral disease and detect problems early ${ }^{(20)}$. The present study reported that the majority of the study subjects visit dentist irregularly and few of them maintain dental visit regularly (Table 2). This result is in agreement with a study done in USA by Manski et al. (2010) which stated that with increasing age, there is a reduction in the utilization of dental services and dental consultations $^{(21)}$. Similar studies from Ibadan; South West Nigeria supported the present study findings ${ }^{(22,23)}$. In contradiction a study done in USA (2000) revealed that two fifths of the elders reported that they go for dental care regularly and more than half of them reported going to dentist only when they have a problem while only few percent never visit the dentist ${ }^{(24)}$.

The main reasons reported for dental health visits were tooth extraction, pain and abscess treatment. While, the least common reason was treatment of inflammation (Table 2). This finding can be explained by the fact that older adults have greater tolerance to bear the pain intensity and this may be a reason for not seeking dental help except when pain is severe and unbearable. This finding is in agreement with a study done in Mansoura, Egypt by Elashri et al. (2014) who stated that the majority of subjects reported that the cause of last dental visit was teeth extraction followed by presence of toothache and to relief pain ${ }^{(25)}$. Furthermore, a study done by Zhu et al. (2005) stated that the most frequent reasons for dental visits were teeth extraction and prosthetic treatment ${ }^{(26)}$. In contrast Nagarjuna et al. (2016) reported that the most common reported reasons for dental visits were pain or dental emergency, followed by restorative treatment ${ }^{(13)}$. 
Maintaining oral health among elders is timely access to dental care; yet, older adults face significant barriers to accessing dental health services. The present study results reported that the majority of the study subjects revealed that high cost of dental care is an important barrier to utilizations of dental services among elderly (Table 3). This is in agreement with previous studies $^{(5,10,27-31)}$.

As for lack of awareness about the importance of dental checkup, the present study showed that the majority of the study subjects reported it as a barrier of dental services use (Table 3). The same finding was reported by Slack-Smith et al. (2010) who stated that lack of awareness was the important barrier to access to the dental health services among the elderly ${ }^{(32)}$. While other studies concluded that low perception of dental need was among the barriers and contribute to low utilization of dental service $^{(33,34)}$. In contrast a study done in USA by Park (2009) revealed that older adults had high perception about the importance of dental checkup and perceived it as a basic need for seeking dental care services on a regular basis ${ }^{(35)}$.

Moreover; the present study results reported that the majority of the study subjects revealed that fear of dental procedure is a dental services utilization barrier among the elderly (Table 3 ). The same results were reported by some studies $^{(3,27)}$. Also, Ajayi and Arigbede (2012) revealed that the major reason for not seeking oral health care services among their subjects was fear ${ }^{(22)}$. In contrast a study conducted by Nitschke et al. (2015) reported that a few of their subjects mentioned fear as reasons for not visiting the dentist ${ }^{(36)}$.

As for difficulty of transportation and long distance to dental services, the present study reported that high percentage of the study subject considers it as barrier to seeking dental care (Table 3 ). In the same line with previous studies reported difficulty of transportation from their homes and travel long distances to get oral health care as a reason for not having dental checkup regularly ${ }^{(13,37)}$. Also, the same result was reported by another study conducted in London by Chideka (2015) ${ }^{(31)}$.

The present study revealed that the probability of the dental health visit among study subjects in the last year was significantly higher among young elderly compared to older elderly (Table 4). This may be due to the effect of physiological changes associated with advancing age, burden of chronic diseases. This finding is in consistent with a study conducted in India by Thomas (2011) who revealed that as age increases people who utilizes dental services decreases ${ }^{(33)}$. Another study conducted in Brazil by Marino et al. (2014) reported that dental health services utilization among elderly was inversely proportional to age ${ }^{(3)}$. On contrary, Silva et al. (2013) and Panchbhai (2012) found that the pattern of dental health visits is not associated with age ${ }^{(38,39)}$.

As for sex, no statistical significant difference was observed between males and females regarding visits to dentists in the last year (Table 4). The same result was reported by Meng et al (2007) and SlackSmith et al. $(2007)^{(27,40)}$. On the other side, a study conducted in India by Nagarjuna et al. (2016) reported that dental visits are lower among females compared to males ${ }^{(13)}$.

Education has a powerful effect on health status of the individuals by increasing the opportunity for being aware of the health benefits, risks and enabling taking the decisions regarding their health problems. The present study results reported that dental health visits were significantly higher among the study subjects with higher educational level and employee (Table 4). This is explained by the fact that educated elderly are more aware of the benefits of dental care and its importance in maintaining healthy teeth. This finding is in agreement with another study which reported that educated employee older adults were more likely to access dental health services and has dental coverage ${ }^{(18)}$. Another study reported that higher 
education may be associated with better dental hygiene habits and relatively high levels of dental services use ${ }^{(41)}$. Also, the same results were reported by a study in Brazil $(2012)^{(42)}$. In the opposite side a study conducted in Burkina Faso (2006) reported that educational attainment is not a factor in probability of dental health visit $^{(43)}$. Also, other studies reported that there was no significant association between level of education and utilization of oral health services ${ }^{(11,44)}$.

As for income, the present study found that the study subjects with enough income have higher dental health visits (Table 4). This finding can be attributed to that the higher income may facilitate paying for such services. The same finding was reported by other studies which stated that those with higher income showed better accessibility to dental care services while poor subjects were less likely to have dental coverage than wealthier older adults ${ }^{(18,29)}$. Also People from relatively low income families were most likely to experience unmet dental care services ${ }^{(33,45)}$. In the opposite side a study done by Varenne et al. (2006) reported that income is not a factor in probability of dental health visit ${ }^{(43)}$.

Elderly persons with diabetes mellitus are more likely to lose their teeth. The percentage of diabetics visiting the dentist increases annually. Poorly controlled diabetes is a risk for dental problems, gums infections and dry mouth $^{(46)}$. In the present study it was observed that dental health visits of the study subjects was significantly higher among elderly with diabetes mellitus and hypertension (Table 5). This can be explained by the fact that elderly patients with DM experience more oral problems that need dental follow up, also the dental follow up is recommended by the physician. These results are supported by other studies conducted in Bangkok, Thailand and Japan reported that diabetes mellitus and hypertension were factors associated with the utilization of dental health services in elderly patients who have oral health problems ${ }^{(47,48)}$. On contrary, a study was done in Johannesburg by Molete MP et al. (2014) reported that presence of chronic illnesses is considered as dental access barriers and contribute to the low dental services utilization $^{(34)}$.

On the other hand, the present study results reported that dental health visits increased significantly among elderly free from liver diseases. This is may be due to persons who have liver disease or multiple chronic diseases can prevent them from obtaining needed dental care and focus on their late health condition and use of medication that impair their activities of daily living. Similar supporting studies reported that poor systemic health and presence of chronic illnesses is considered as dental access barriers and contribute to the low dental services utilization ${ }^{(11,44)}$.

Behavioral aspects play a major role in the prevention of both dental caries and disease. Adequate oral hygiene habits and compliance with regular preventive dental visits are essential for good oral health status and prevention of oral diseases ${ }^{(49)}$. The present study results reported that dental health visits was significantly higher among elderly who have good oral health status compared to those with bad oral health status (Table 6). This finding may be explained by the fact that regular dental health visits help to solve oral health problems early and prevent negative effect on oral health status. In the same line a study conducted in Mansoura, Egypt by Elashri et al. (2014) revealed that the more regular dental visits the healthier the oral health status ${ }^{(25)}$. Another study reported that the most influential variable for the utilization of dental services was dental health status ${ }^{(36)}$.

The present study results reported that dental health visits are significantly higher among elderly who are independent in performing activities of daily living. This is in accordance with a study done in Canada by Douglas et al. (2008) revealed that dental visitation was significantly higher among independent elderly and those with fewer 
restriction in performing activity of daily living $^{(50)}$.

\section{Conclusion}

It can be concluded from the present study results that high cost of dental care, lack of awareness about importance of dental health visits, fear of dental procedure, difficulty of transportation and long distance were identified as main barriers toward utilization of dental services. Predictors of dental health visits among elderly were basic and secondary education, enough income, elderly suffering from hypertension and elderly free from liver diseases Also, elderly with healthy oral status.

\section{Recommendations}

Based on the results of the study, the following recommendations are suggested:

- Design oral health educational program for community dwelling elderly about the importance of oral health routine checkup and the available community dental health services affiliated to Mansoura city and motivating them to use these services.

- Raise awareness of community dwelling older adults who attained the elderly clubs, outpatient clinics and in assisted living facilities regarding importance of utilizing health insurance hospitals to overcome cost of dental health services.

\section{Acknowledgement}

The researchers are thankful to all elders attending geriatric outpatients' clinics who participated in this study; also they appreciate help provided by the directors affiliated to each outpatient clinic in conduction of the study. 
Table (1): Distribution of the study subjects according to their socio-demographic characteristics

\begin{tabular}{|c|c|c|}
\hline \multirow{2}{*}{ Items } & \multicolumn{2}{|c|}{ Study subjects } \\
\hline & $N_{=}(612)$ & $(\%)$ \\
\hline \multicolumn{3}{|l|}{ Age: } \\
\hline $60-$ & 500 & 81.7 \\
\hline $75-$ & 84 & 13.7 \\
\hline $80+$ & 25 & 4.6 \\
\hline Mean \pm SD & \multicolumn{2}{|c|}{$67.91 \pm 6.56$} \\
\hline \multicolumn{3}{|l|}{ Sex: } \\
\hline Male & 331 & 54.1 \\
\hline Female & 281 & 45.9 \\
\hline \multicolumn{3}{|l|}{ Current marital status: } \\
\hline Married & 409 & 66.8 \\
\hline Unmarried* & 203 & 33.2 \\
\hline \multicolumn{3}{|l|}{ Education: } \\
\hline Illiterate & 320 & 46.3 \\
\hline Basic education** & 170 & 24.6 \\
\hline Secondary education & 82 & 13.4 \\
\hline University education & 40 & 6.6 \\
\hline \multicolumn{3}{|l|}{ Occupation: } \\
\hline . Housewives & 246 & 35.6 \\
\hline Employees & 127 & 18.4 \\
\hline Farmers & 120 & 17.4 \\
\hline Skilled workers & 94 & 13.6 \\
\hline · $\quad$ Unskilled workers & 25 & 3.6 \\
\hline \multicolumn{3}{|l|}{ Income: } \\
\hline - Enough \& enough and save & 177 & 28.9 \\
\hline Not enough & 435 & 71.1 \\
\hline
\end{tabular}

*Widowhood, divorced and single,

**Basic education (primary and preparatory) 
Table (2): Distribution of the study subjects according to their medical diagnosis and reasons of last visit to dental clinic

\begin{tabular}{|c|c|c|}
\hline \multirow{2}{*}{ Items } & \multicolumn{2}{|c|}{ Study subjects } \\
\hline & $N_{=}(612)$ & $\%$ \\
\hline $\begin{array}{l}\text { Health history\#: } \\
\quad \text { Diabetes mellitus }\end{array}$ & 303 & 49.5 \\
\hline . Hypertension & 220 & 35.9 \\
\hline . $\quad$ Musculoskeletal disorders & 203 & 33.2 \\
\hline Cardiac disorders & 201 & 32.8 \\
\hline . Hepatic disorders & 103 & 16.8 \\
\hline . $\quad$ Urological disorders & 98 & 16.0 \\
\hline . $\quad$ Respiratory disorders & 67 & 10.9 \\
\hline . $\quad$ Cancer & 24 & 3.9 \\
\hline \multicolumn{3}{|l|}{ Visit to dental clinic: } \\
\hline Yes & 270 & 44.1 \\
\hline . No & 342 & 55.9 \\
\hline $\begin{array}{l}\text { Pattern of dental health visits: } \\
\quad \text {. Irregular visit }\end{array}$ & $\begin{array}{c}(270) \\
190\end{array}$ & 70.4 \\
\hline . Regular (twice per year) & 80 & 29.6 \\
\hline $\begin{array}{l}\text { Reasons of the last dental health services utilization\#: } \\
\text {. Extractions }\end{array}$ & $\begin{array}{c}(270) \\
227\end{array}$ & 37.1 \\
\hline . Filling & 163 & 26.6 \\
\hline Cleaning & 60 & 9.8 \\
\hline . $\quad$ Denature installation & 35 & 5.7 \\
\hline . Inflammation & 11 & 1.8 \\
\hline . $\quad$ Abscess & 5 & 0.8 \\
\hline
\end{tabular}

\#More than one answer

Table (3): Barriers of dental health services utilization of the study subjects during the last year

\begin{tabular}{||c|c|c||}
\hline Barriers \# & $\mathbf{N}_{=}(\mathbf{6 1 2})$ & $\mathbf{( \% )}$ \\
\hline$\cdot \quad$ High cost of dental care & 491 & 80.0 \\
\hline$\cdot \quad$ Lack of awareness about dental checkup & 454 & 74.2 \\
\hline$\cdot$ Fear of dental procedure & 386 & 63.1 \\
\hline Difficult transportation and long distance & 367 & 60.0 \\
\hline . Bad past experience & 289 & 47.2 \\
\hline$\cdot \quad$ Infection & 125 & 20.4 \\
\hline
\end{tabular}

\#Categories are not mutually exclusive 
Table (4): Relation between socio-demographics characteristics of the study subjects and dental health visits during the last year

\begin{tabular}{|c|c|c|c|c|}
\hline Items & $\begin{array}{c}\text { Total } \\
N=612\end{array}$ & $\begin{array}{l}\text { Visit to dentist } \\
\mathrm{N}=270(44.1)\end{array}$ & $\mathbf{P}$ & $\begin{array}{c}\text { COR } \\
(95 \% \mathrm{CI}) \\
(\mathbf{4 0 . 2 - 4 8 . 1 )}\end{array}$ \\
\hline \multicolumn{5}{|l|}{ Age: } \\
\hline $60-$ & 500 & $245(49.0)$ & 0.04 & $2.4(1.1-5.6)$ \\
\hline $75-$ & 84 & $17 \quad(20.2)$ & 0.4 & $0.6(0.2-1.7)$ \\
\hline . $\quad 85+$ & 28 & $8 \quad(28.6)$ & & $1(\mathrm{r})$ \\
\hline \multicolumn{5}{|l|}{ Sex: } \\
\hline Male & 331 & $141(42.6)$ & 0.4 & $0.9(0.6-1.2)$ \\
\hline . Female & 281 & $129(45.9)$ & & $1(\mathrm{r})$ \\
\hline \multicolumn{5}{|l|}{ Current marital status: } \\
\hline . Married & 409 & $190(46.5)$ & 0.1 & $1.3(0.9-1.9)$ \\
\hline . Unmarried & 203 & $80(39.4)$ & & $1(\mathrm{r})$ \\
\hline \multicolumn{5}{|l|}{ Education: } \\
\hline . Illiterate & 320 & $116(36.2)$ & 0.4 & $1(\mathrm{r})$ \\
\hline Basic & 170 & $55(32.4)$ & $\leq 0.001$ & $0.8(0.6-1.2)$ \\
\hline . Secondary & 82 & $71(86.6)$ & $\leq 0.001$ & $11.4(5.7-22.3)$ \\
\hline - University & 40 & $28(70.0)$ & & $4.1(2.0-8.4)$ \\
\hline \multicolumn{5}{|l|}{ Occupation: } \\
\hline . Housewives & 246 & $98(39.8)$ & 0.1 & $1.5(0.9-2.4)$ \\
\hline . Employees & 127 & $99(78.0)$ & $\leq 0.001$ & $7.9(4.5-14.0)$ \\
\hline Farmers & 120 & $37(30.8)$ & & $1(\mathrm{r})$ \\
\hline Skilled workers & 94 & $27(28.7)$ & 0.7 & $0.9(0.5-1.6)$ \\
\hline . Unskilled workers & 25 & $9(36.0)$ & 0.6 & $1.3(0.5-3.1)$ \\
\hline \multicolumn{5}{|l|}{ Income: } \\
\hline . Enough & 177 & $103(58.2)$ & $\leq 0.001$ & $2.2(1.6-3.2)$ \\
\hline Not enough & 435 & $167(38.7)$ & & $1(\mathrm{r})$ \\
\hline
\end{tabular}


Table (5): Relation between medical diagnosis and dental health visits of the study subjects during the last year

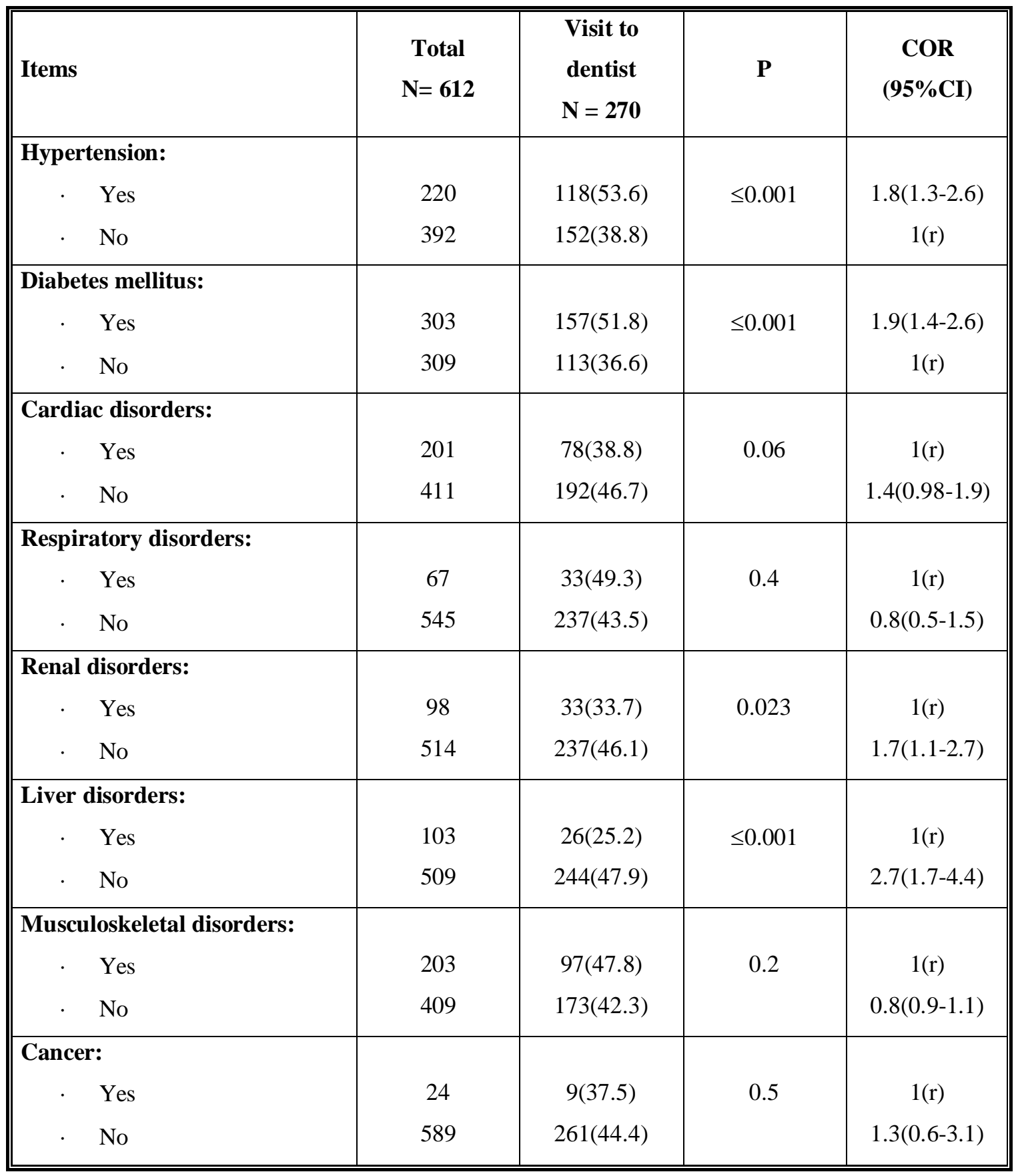


Table (6): Relation between oral health status and ability of the study subject to perform ADL and dental health visits during the last year

\begin{tabular}{|c|c|c|c|c|}
\hline Items & $\begin{array}{c}\text { Total } \\
N=612\end{array}$ & $\begin{array}{c}\text { Visit to } \\
\text { dentist } \\
\mathrm{N}_{=} 270\end{array}$ & $\mathbf{P}$ & $\begin{array}{c}\text { COR } \\
(95 \% \text { CI })\end{array}$ \\
\hline $\begin{aligned} \text { OHAT score: } \\
\cdot \quad \text { Healthy }(0-3) \\
\cdot \quad \text { Changes }(4-8) \\
\cdot \quad \text { Unhealthy }(9 \& \text { more }) \\
\end{aligned}$ & $\begin{array}{c}227 \\
354 \\
31 \\
\end{array}$ & $\begin{array}{c}140(61.7) \\
124(35.0) \\
6(19.4) \\
\end{array}$ & $\begin{array}{c}\leq 0.001 \\
0.07\end{array}$ & $\begin{array}{c}6.7(2.6-7.0) \\
2.2(0.9-5.6) \\
1(\mathrm{r}) \\
\end{array}$ \\
\hline $\begin{array}{cl}\text { ADL: } & \\
\cdot & \text { Independent } \\
\cdot & \text { Needs assistance } \\
. & \text { Dependent } \\
\end{array}$ & $\begin{array}{c}369 \\
232 \\
14\end{array}$ & $\begin{array}{c}234(63.4) \\
31(13.4) \\
5(35.7)\end{array}$ & $\begin{array}{l}0.04 \\
0.02\end{array}$ & $\begin{array}{c}3.1(1.1-9.6) \\
0.3(0.1-0.9) \\
1(\mathrm{r})\end{array}$ \\
\hline
\end{tabular}

$\mathrm{COR}_{=}$Crude odds $\quad C I_{=}$confidence interval $\quad r_{=}$reference category

$A D L_{=}$Activities of Daily Living $\quad O H A T_{=}$Oral Health Assessment Tool

Table (7): Logistic regression analysis of dental health visits during the last year and its associated independent factors

\begin{tabular}{|c|c|c|c|}
\hline Items & B & $\mathbf{P}$ & AOR (95\%CI) \\
\hline Education: & & & \\
\hline Illiterate & - & & $1(\mathrm{r})$ \\
\hline Basic & -0.5 & 0.017 & $0.6(0.4-0.9)$ \\
\hline Secondary & 1.3 & 1.001 & $3.8(1.8-8.2)$ \\
\hline Above secondary & -0.2 & 0.7 & $0.8(0.3-2.0)$ \\
\hline Income: & & & \\
\hline Enough & 0.6 & 0.014 & $1.8(1.1-2.9)$ \\
\hline Not enough & - & & $1(\mathrm{r})$ \\
\hline Hypertension: & & & \\
\hline Yes & 0.8 & $\leq 0.001$ & $2.2(1.5-3.3)$ \\
\hline No & - & & $1(\mathrm{r})$ \\
\hline Hepatic disorders: & & & \\
\hline Yes & - & & $1(\mathrm{r})$ \\
\hline No & 0.8 & 0.003 & $2.2(1.3-3.7)$ \\
\hline OHAT score: & & & \\
\hline Healthy (0-3) & 1.1 & 0.04 & $2.9(1.05-8.2)$ \\
\hline Changes (4-8) & 0.5 & 0.3 & $1.6(0.6-4.3)$ \\
\hline Unhealthy ( $9 \&$ more) & - & & $1(r)$ \\
\hline
\end{tabular}

AOR=Adjusted odds ratio $\quad C I=$ confidence interval $\quad r=$ reference category 


\section{References}

1. Lol E.C.M, H.C. Lin, Z.J. WAN, M.C.M. Wong: Utilization of Dental Services in Southern China J Dent Res 2001; 80(5):14711474 .

2. Gibson B: Access to Dental Services. In: Gulliford M, Morgan M, editors. Access to health care. London: Routledge 2003; 174188.

3. Marino R, Khan A, Tham A, Khew C, Stevenson C: Pattern and Factors Associated With Utilization of Dental Services among Older Adults in Rural Victoria Australian Dental J 2014; 59: 504510.

4. Kelly MSJ, Nuttall N, Bradnock G, Morris J, Nunn J, Pine C, Pitts N, Treasure E, White D: Adult dental health survey: oral health in the UK 1998. The Stationery Office. 2000; London.

5. Active Registrations and Take-up Rates per 100 Local Population of Patients aged 18 and over by Health Body\# and Age Band at end March 2006: PCT. [http://www.dpb.nhs.uk/archive/nhs_statistics /tables/reg_a2bb_formatted.htm]

6. Marino R, Giacaman R. Patterns of use of oral health care services and barriers to dental care among ambulatory older Chilean. BMC Oral Health (2017); 17(38): 1-7.

7. Al-jabr A and Alhujaili A. "Cost as a Barrier to Access Dental Healthcare in Saudi Patients". Oral Health and Dentistry 2018; 2(4): 401-409.

8. El-Lassy R: Oral health status of elderly living in residential homes at Damanhour City, Egypt. ASNJ 2014; 16 (1): 93-122.

9. Heaton LJ, Smith TA, Ray bould TP: Factors Influencing Use of Dental Services in Rural and Urban Communities: Considerations for practitioners in underserved areas. J Dent Educ 2004; 68:1081-9.

10. Kiyak HA \& Reichmuth M: Barriers to and Enablers of Older Adults' Use of Dental Services. Journal of Dental Education 2005; 96: 975-986. Retrieved From
http://www.Ncbi.Nlm.Nih.Gov/Pubmed/1614

$\underline{1083}$.

11. Vikram Simha Bommireddy, Krishna Mohan Koka, Srinivas Pachava, Suresh Sanikommu, Srinivas Ravoori, and Viswa Chaitanya Chandu. Dental Service Utilization: Patterns and Barriers among Rural Elderly in Guntur District, Andhra Pradesh J Clin Diagn Res. 2016; 10(3): 4347.

12. Borreani E, Wright $\mathrm{D}$, Scambler $\mathrm{S}$ and Gallagher J. Minimising barriers to dental care in older people. BMC Oral Health 2008; 8(7): 1-15.

13. Nagarjuna P, Reddy VC, Sudhir KM, Kumar RK, Gomasani S: Utilization of Dental Health-Care Services and Its Barriers among The Patients Visiting Community Health Centers in Nellore District, Andhra Pradesh: A cross-sectional, questionnaire study. J Indian Assoc Public Health Dent 2016; 14:451-5.

14. Katz S, Akpom C: Index of ADL: A standardized Measure of Biological and Psychological Function. International $\mathrm{J}$ of Health Science 1976; 6(6):123-40.

15. Melis A, Elshazly S: Assessment of Activity of Daily Living and Mental Status of Elderly Residing In Dar Mohamed Ragab. Unpublished paper submitted to faculty of nursing. Alexandria University 1999.

16. Chalmers, Jane Margaret; King, Peter L; Spencer, Andrew John; Wright, F. A.; Carter, Knute Derek: The oral health assessment tool - Validity and reliability Australian Dental Journal 2005; 50(3):191-199.

17. Kayser-Jones J: Strategies for Conducting Dental Examinations among Cognitively Impaired Nursing Home Residents. Special Care Dentistry 1996; 16:46-52.

18. Ninan E: Access To Oral Care -A Systematic Review Of A Continuing Public Health Issue Among Older Adults the University Of Texas School Of Public Health Houston, Texas May 2011.

19. Theris A \& Kathleen F: Ebersole and Hess' Gerontological Nursing Healthy Aging, 3rd ed. Mosby Company. 2010; 107-9. 
20. Ferreira C, Antunes J, Andrade F: Factors Associated With the Use of Dental Services by Elderly Brazilians Rev. Saúde Pública 2013; (47): 3 São Paulo.

21. Manski RJ, Moeller J, Chen H, Schimmel J et al: Dental utilization and Retirement. Public Health Dentistry J 2010; 70:67-75 (C) 2009 American Association of Public Health Dentistry.

22. Ajayi DM, Arigbede AO: Barriers to oral health care utilization in Ibadan, South West Nigeria African Health Sciences 2012; (4): 507-513. http://dx.doi.org/10.4314/ahs.v12i4.17.

23. Fiske J. The Delivery of Oral Care Services to Elderly People Living in a Non Institutionalized Setting. Public health dent J 2010; 60: 321-325

24. USA Department of Health and Human Services: Oral Health in America: National Institutes of Health. A Report of the Surgeon General. 2000 .

25. Elashri N, Abd El Fattah N, Abd el-latif A, Abd elhameed S: The Effect of Oral Health Care Interventions on Oral Health Related Quality of Life of Institutionalized Older Adults; Unpublished doctoral thesis, Mansoura University 2014.

26. Zhu L, Petersen PE, Wang HY, et al: Oral Health Knowledge, Attitudes and Behavior of adults In China. Int. Dent. J 2005; 55: 231241.

27. Meng X, Heft MW, Bradley MM, Lang PJ: Effect of Fear on Dental Utilization Behaviors and Oral Health Outcome. Community Dent Oral Epidemiol 2007; 35(4):292-301.

28. Alfaro DP, Ahluwalia KP: Oral Care Needs Barriers and Challenges among Community Dwelling Elderly in New York State and northern Manhattan. NY State Dent J 2010; 76(5):38-41.

29. Shelley D: Barriers to Dental Services for Older Adults American journal of health behavior; 2014.

30. Bahadori M, Ravangard R, Asghari B: Perceived Barriers Affecting Access to
Preventive Dental Services: Application of Dematel Method Health Management Research Center, Baqiyatallah University of Medical Sciences, Tehran, IR Iran 2013.

31. Chideka K, Klass C, Dunne S and Gallagher J.E. Listening to older adults: community consultation on a new dental service, Community Dental Health 2015; 32: 231236.

32. Slack-Smith L, Lange A, Paley G, O'grady M: Oral health and access to dental care: a qualitative investigation among older people in the community Gerodontology.2010; https://doi.org/10.1111/j.17412358.2009.00320.x, 2009, 1-9, which has been published in final form at 10.1111/ j.1741-2358.2009.00320.x.

33. Thomas S: Barriers to Seeking Dental Care among Elderly in a Rural South Indian Population (Journal of the Indian Academy of Geriatrics 2011; 7: 60-65.

34. Molete MP, Yengopal V, Moorman J: Oral Health Needs and Barriers to Accessing Care among the Elderly in Johannesburg Department of Community Dentistry, Faculty of Health Sciences, University of the Witwatersrand. 2014; E-mail: Mpho.molete@wits.ac.za.

35. Park DS: Challenges of Delivering Oral Health Care to Older Adults. N Y State Dent J 2009; 75(5):36-40.

36. Nitschke I, Stillhart A, Kunze J: Utilization Of Dental Services in Old Age, Developments In Dental Practice Clinic For Dentistry For The Elderly and Disabled, Centre For Dentistry, University Of Zurich Swiss Dental Journal. 2015; 4:125.

37. Jain VK, Sequeira P, Jain J, Chancy U, Maliyil MJ, Bhagwandas SC. Barriers in utilization of oral health care services among patients attending primary and community health centres in Virajpet, South Karnataka. Nat J Med Dent Res 2013; 1:39-47.

38. Silva AR, Langlois CO, Feldens CA: Use of Dental Services and Associated Factors among Elderly in Southern Brazil. Rev Bras Epidemiol 2013; 16: 1005-1016. 
39. Panchbhai AS: Oral Health Care Needs in the Dependant Elderly in India. Indian J Palliat Care 2012; 18:19-26.

40. Slack-Smith LM, Mills CR, Bulsara MK, O'Grady MJ. Demographic, health and lifestyle factors associated with dental service attendance by young adults. Aust Dent J 2007; 52:205-9.

41. Qiu Y\&Ni H: Utilization of Dental Care Services by Asians and native Hawaiian or other Pacific Islanders: United States, 19972000. Adv Data. 2003 June 10; 336.

42. Machado LP, Camargo MBJ, Jeronymo JCM, Bastos GAN: Regular Use of Dental Services among Adults and Older Adults in A vulnerable Region in Southern Brazil: Rev Saude Publica 2012; 46(3):526-33.

43. Varenne B, Petersen PE, Fournet F, Msellati $\mathrm{P}$, Gary J, Ouattara S, et al: Illness-Related Behaviour and Utilization of Oral Health Services among Adult City-dwellers in Burkina Faso: Evidence From A Household Survey. BMC health services research 2006; 6: 164

44. Goudge J, Gumede T, Russel S, Gilson L, Mills A: The SACOCO Study: Poor Households and the Health System. Written submissions to the Public Inquiry into access to health care system 2007.
45. Kiyak, H.A: Disparities in Access to Dental Care. Geriatric Oral Health Care. Marquette University. 2004.

46. Ira B, Lalla E, Wenche S, Borgnakke, et al: The Relationship between Oral Health and Diabetes Mellitus: JADA 2008; 139(10):1924.

47. Saengtipbovorn S, Taneepanichskul S, Pongpanich S, et al: Factors Associated With The Utilization Of Dental Health Services By The Elderly Patients In Health Center No.54, Bangkok, Thailand J Health Res 2012; 26(4): 199-204.

48. Ohi T, Sai M, Kikuchi M, Hattori M, Tsuboli A, Hozawa a et al: Determinants of The Utilization of Dental Services in A Community-Dwelling elderly Japanese population. Tohoku J Exp Med 2009; 218(3): 241-9.

49. Ashraf S: Self reported oral Health and Oral Health Practices among Bangladeshi Immigrants In, Norway University of Oslo, The Faculty of Medicine Institute of Health and Society Department of Community Medicine 2017.

50. Douglas J. Brothwell, MSc; Michelle Jay, DMD; Dieter J. Schönwetter. Dental Service Utilization by Independently Dwelling Older Adults in Manitoba, Canada .JCDA J 2008; 74(2): 161-67. 